\title{
Mitotane Regimen
}

National Cancer Institute

\section{Source}

National Cancer Institute. Mitotane Regimen. NCI Thesaurus. Code C160088.

A chemotherapy regimen consisting of mitotane that may be used in the treatment of adrenocortical carcinomas. 